\title{
The Impact of Myofascial Release on Vital Capacity and Diaphragmatic Excursion in Postsurgical Pleural Effusion
}

\author{
MOHAMED M. EL-KADY, M.Sc.*; HANY E. OBAYA, Ph.D.*; AWNY F. RAHMY, Ph.D.** and \\ MOHAMED MAHMOUD EL-BATANONI, M.D.** \\ The Department of Cardiovascular/Respiratory Disorders and Geriatrics, Faculty of Physical Therapy* and \\ The Department of Occupational Medicine, Faculty of Medicine**, Cairo University
}

\begin{abstract}
Background: Accumulation of fluid in pleural space may affect on function of respiratory muscles primarily because of increase of chest wall volume. Force-length relationship of respiratory muscles indicate that for a given neural activation, the pressure developed by muscles decrease with decreasing length. An increase of chest wall volume decrease length of respiratory muscles mainly diaphragm and increase of expiratory muscles length. It follows that with pleural effusion, all else being the same for a given, neural activation, pressure developed by the inspiratory and expiratory muscles should decrease and increase, respectively. So, the aim of the study to maintain flexibility of the diaphragm and intercostal muscles in order to get the optimum action of theses muscles, increase chest expansion, improve the respiratory function of these patients.
\end{abstract}

Aim of Study: To evaluate the effect of of myofascial release for diaphragm and intercostal muscles on vital capacity and diaphragmatic excursion in post surgical pleural effusion.

Subject and Methods: Forty subjects (male only) were randomly assigned into two groups equal in number. (Study group A): Consisted of 20 patients was enrolled in the myofascial release protocol in addition to traditional physical therapy program for pleural effusion. (Study group B): Consisted of 20 patients was enrolled in the traditional physical therapy program for pleural effusion only. Their vital capacity and diaphragmatic excursion were measured before and after 8 weeks of training program for both groups. The myofascial release protocol performed a 1-hour session 3 times a week for 8 weeks.

Results: Group (A) myofascial release group, showed a statistical significant improvement in vital capacity and diaphragmatic excursion, that was $13.49 \%$, more than the improvement in group (B) traditional physical therapy group, that was $8.68 \%$.

Conclusions: The myofascial release for diaphragm and intercostal muscles is effective on vital capacity and diaphragmatic excursion in post surgical pleural effusion.

Correspondence to: Dr. Mohamed M. El-Kady, The Department of Cardiovascular/Respiratory Disorders and Geriatrics, Faculty of Physical Therapy, Cairo University
Key Words: Pleural effusion-Myofascial release-Diaphragm - Intercostal muscles - Vital capacity - Diaphragmatic excursion.

\section{Introduction}

A PLEURAL effusion is an abnormal collection of fluid in the pleural space resulting from excess fluid production or decreased absorption or both. It is the most common manifestation of pleural disease, with etiologies ranging from cardiopulmonary disorders to symptomatic inflammatory or malignant diseases requiring urgent evaluation and treatment [1]

In summary, the present studies showed that: (1) Pleural effusion impairs the lung-expanding capacity of the diaphragm; (2) This impairment is compensated for by an increase in neural drive to the inspiratory intercostals and the diaphragm, so that the pleural pressure swings during breathing remain unaltered; and (3) Because the action of the diaphragm during effusion is impaired more than that of the inspiratory intercostals, the relative pressure contribution of these muscles is increased [2].

Maintaining respiratory muscle function is of vital importance for the respiratory system, just as the heart muscle is for the circulatory system. These muscles are fundamental in the maintenance of respiratory mechanics, and, under physiopathological conditions, muscle force is altered, which is reflected as a reduction in the respiratory pressures [3]

Fascia remains too often medically neglected as the underlying cause of problems, nevertheless, hands-on therapist have been aware of its great importance for a long time. Bones, organs and 
muscles are seen to float within the fascial net, the uninterrupted three-dimension connective tissue system. It's plastic and visco-elastic properties of changing the tension and shape under the influence of manual techniques and motion re-education, enables structural changes to be reversible. Variety of techniques, such as deep tissue massage and myofascial release are used to awaken, lengthen and reposition the fascia, release its adhesions and apply the great awareness of movement education [4].

Myofascial release is a very effective, gentle and safe hands-on method of soft tissue mobilization, involves applying gentle sustained pressure to the subcutaneous and myofascial connective tissue. This low load sustained stretch gradually, over time, allow the myofascial tissue to elongate and relax, thus allowing increased range of motion, flexibility and decreased pain [5].

Decreased FVC is a common feature of restrictive disease. Any disease that affects the action of the chest or dispensability of lung tissue, itself tends to reduce FVC. This space occupying lesion (pleural effusion) reduces FVC by compressing surrounding lung tissue. Restrictive diseases such as pleural disorder or pleural effusion may cause $\mathrm{FEV}_{1}$ to be reduced. Reduction of FEV ${ }_{1}$ occurs in much the same way as reduction in FVC [6].

Mechanical restriction of diaphragmatic excursion can promote imbalance in the ventilation/ perfusion ratio, causing hypoventilation in ventilatory-dependent areas of the lung. Therefore, both diaphragmatic weakness and failure of muscle recruitment increase the incidence of atelectasis and subsequent respiratory infections, which occur more frequently in the lung bases. The decreased mobility of the rib cage and diaphragmatic excursion has a negative effect on the ability to generate pulmonary pressure gradients this result in reduced exercise tolerance and dyspnea [7]

Diaphragmatic excursion can be readily studied with fluoroscopy. However, fluoroscopy is not portable and requires ionizing radiation. An alternative method is ultrasonography. Recent studies have reported that M-mode ultrasonography is reproducible, reliable, and relatively easy to use for analyzing diaphragmatic excursion [8]

\section{Subjects and Methods}

Forty post-operative pleural effusion patients, were included in this study. They were recruited from pulmonary rehabilitation unit in the chest department at Ain Shams University Hospitals, in addition to Physical Therapy Department in ElKatamyea Medical Center. The practical work of the study was carried out in the period starting from Feb. 2017 till August 2017.

\section{Inclusion criteria:}

Post-operative pleural effusion male patients, their age ranged from 40-60 years old and their Body Mass Index (BMI) below $30 \mathrm{~kg} / \mathrm{m}^{2}$.

\section{Exclusion criteria:}

Pneumothorax and hydropneumothorax, systemic diseases leading to pleural effusion like (cardiovascular, renal, hepetic), brochial asthma, COPD, Obese patients (BMI $>30.0 \mathrm{~kg} / \mathrm{m}^{2}$ ), massive ascites, hiatus hernia, bone deformity in spine affect on chest wall as kyphoscoliosis.

Subjects were randomly assigned to two groups equal in number:

(Study group A): Was enrolled in the myofascial release protocol in addition to traditional physical therapy program for pleural effusion.

(Study Group B): Was enrolled in traditional physical therapy program for pleural effusion only.

The vital capacity and diaphragmatic excursion were measured before and after 8 weeks of training program for both groups.

The myofascial release protocol performed a 1-hour session 3 times/week for 8 weeks.

\section{Instrumentation:}

Using objective assessment tools including:

1 - Ultrasonography.

2- Spirometry.

\section{Using objective theraputic tools including:}

- Free weight and sand bags their weight ranged from 2-4 g used for applying resistance to diaphragm.

- Belt for applying unilateral localized breathing exercise.

- Incentive spirometry.

\section{Evaluation procedures:}

The assessment of pulmonary function by Spirometry according to Fahy et al., (2014) protocol [9]:

- The test for was taken using a portable spiromaster PC-10.

- Release of any tight clothing. 
- Each patient was entered into the program database on laptop before beginning and record patients' data (name, age, weight, height, and sex) in the PFT apparatus.

- The patient stands with thorax in a nearly vertical way; with the chin elevated slightly.

- The patient was given verbal instruction on how to perform the test.

- The participant was given a nose clip and a mouthpiece.

- The patient asked to blow through the mouth piece forced and as long as much possible.

- At the end of exhalation, they removed the mouthpiece and breathed normally.

- The measured values was be compared to the predicted values values.

The assessment of diaphragmatic excursion by ultrasonography:

Diaphragmatic Excursion (DE) were measured using a real time sonographic system with a 3.8 MHz convex probe (Aloka prosound 4000, Aloka, Japan ultrasound machine) at a depth of $22-24 \mathrm{Cm}$. The probe is placed immediately below the right costal margin in the mid-clavicular line and is directed medially, cephalad and dorsally, so that the ultrasound beam reaches perpendicularly the posterior third of the corresponding hemidiaphragm. The two-Dimensional (2D) mode is initially used to obtain the best approach and select the exploration line; the M-mode is then used to display the diaphragmatic excursion (displacement per $\mathrm{cm}$ ) [10] .

\section{Treatment procedure:}

(Study group A):

Myofascial release treatment session:

1- Intercostal muscles release technique.

2- Diaphragm release technique.

1- Myofascial release of intercostal muscles (intercostal rib release):

Technique of the gross stretch for rib cage:

The patient is then instructed to take a deep breath. During the exhalation phase, the therapist applies gentle downward pressure (caudally directed) on the patient's lower ribs to facilitates release of the lower ribs. The patient is instructed to reach overhead toward the opposite shoulder during exhalation, which accentuates the stretch of the intercostal muscles [11].
Technique of the focused stretch for intercostal muscles:

Perform a foucsed stretch of the intercostals using both thumbs placed parallel to each other on the inferior border of the upper rib and the superior border of the lower rib. Stretch by pushing the ribs apart. Hold, wait for the release and stretch again. The therapist move to the next section of the intercostals, relying on feedback to focus the stretch while working around the rib cage. This procedure should take approximately one-and-a-half to two minutes at every level [11]

\section{2- Diaphragm release:}

The patient position: Supine with the knees and hips both at approximately $90^{\circ}$ of flexion. The therapist performed manual contact (pisiform, ulnar edge and the last three fingers pads) with the underside of the costal cartilage of the 7 th, 8 th, 9 th and 10 th rib, and guiding forearms toward the shoulders of the corresponding side. In the inspiratory phase, the therapist gently pulled the points of contact with both hands, in the direction of the head, yet slightly lateral, accompanying the elevation movement of the ribs. During exhalation, the therapist deepened contact toward the inner costal, maintaining resistance throughout the inspiratory phase. This maneuver was performed in two sets of ten deep breaths, with a one minute interval between them [12].

\section{(Study group B):}

Group (B) will receive traditional physiotherapy program for pleural effusion only.

Traditional physiotherapy program for pleural effusion will include:

1- Positioning: On sound side 15 minutes to improve ventilation and on the affected side for reducing the pain.

\section{2- Deep breathing exercise:}

- Diaphragmatic breathing exercise.

- Unilateral localized breathing exercise from sound side-lying position.

3-Diaphragm strengthening: After the placing the patient in supine, the therapist places a sand bag on the epigastric region to resist diaphragm excursion.

4- Incentive spirometry.

\section{5- Pleural stretching:}

A- Wring position: With both knees in 90 flexion, touch plinth with your knees toward sound side, then raise arm over the head and rotate the 
head toward affected side. Maintain 15-30 seconds/ 3 times.

B- Phalanx position: From supine posirion, ask patient to touch left knee with left hand on the sound side, then raise arm over the head and rotate the trunk toward sound side. Maintain 15-30 seconds $/ 3$ times.

\section{Results}

Comparison of FVC between Group (A) and $\operatorname{Group}(B)$ :

Table (1): Comparison of FVC between Groups A and B.

\begin{tabular}{|c|c|c|}
\hline \multirow[b]{2}{*}{ Items } & \multicolumn{2}{|c|}{$\mathrm{FVC}$} \\
\hline & $\begin{array}{l}\text { Pre- } \\
\text { treatment }\end{array}$ & $\begin{array}{l}\text { Post- } \\
\text { treatment }\end{array}$ \\
\hline Pulmonary function tests (Group A) & $2.26 \pm 0.45$ & $2.51 \pm 0.58$ \\
\hline Diaphragmatic excursion (Group B) & $2.44 \pm 0.44$ & $2.57 \pm 0.50$ \\
\hline$t$-value & 1.269 & 0.386 \\
\hline Level of significance ( $p$-value) & 0.212 & 0.702 \\
\hline Significance $(p<0.05)$ & NS & NS \\
\hline
\end{tabular}

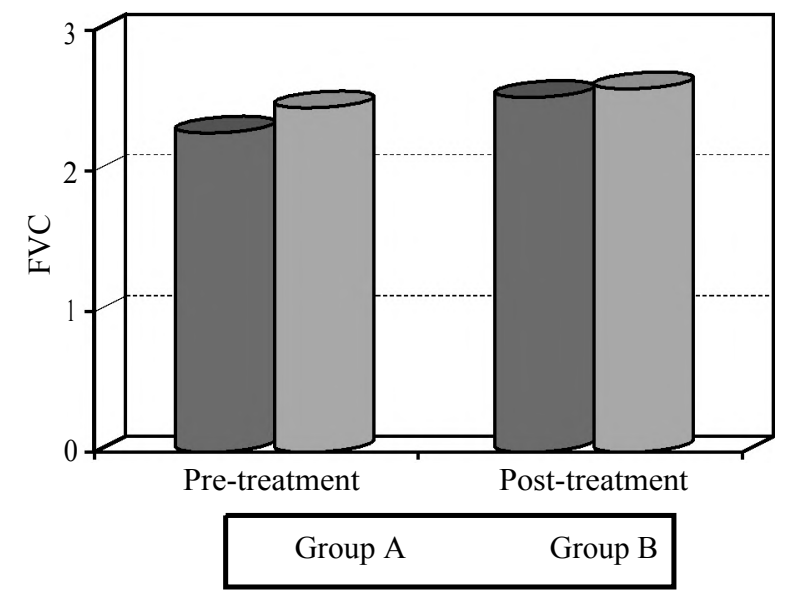

Fig. (1): Show mean values of FVC for Group A and Group B.

Comparison of DE between Group (A) and Group (B):

Table (2): Comparison of DE between Groups A and B.

\begin{tabular}{lll}
\hline \multirow{2}{*}{ Items } & \multicolumn{2}{c}{ DE } \\
\cline { 2 - 3 } & $\begin{array}{c}\text { Pre- } \\
\text { treatment }\end{array}$ & $\begin{array}{c}\text { Post- } \\
\text { treatment }\end{array}$ \\
\hline Pulmonary function tests (Group A) & $1.57 \pm 0.44$ & $1.82 \pm 0.57$ \\
Diaphragmatic excursion (Group B) & $1.33 \pm 0.39$ & $1.49 \pm 0.47$ \\
$t$-value & 1.812 & 1.982 \\
Level of significance $(p$-value) & 0.078 & 0.055 \\
Significance $(p<0.05)$ & $\mathrm{NS}$ & $\mathrm{NS}$ \\
\hline
\end{tabular}

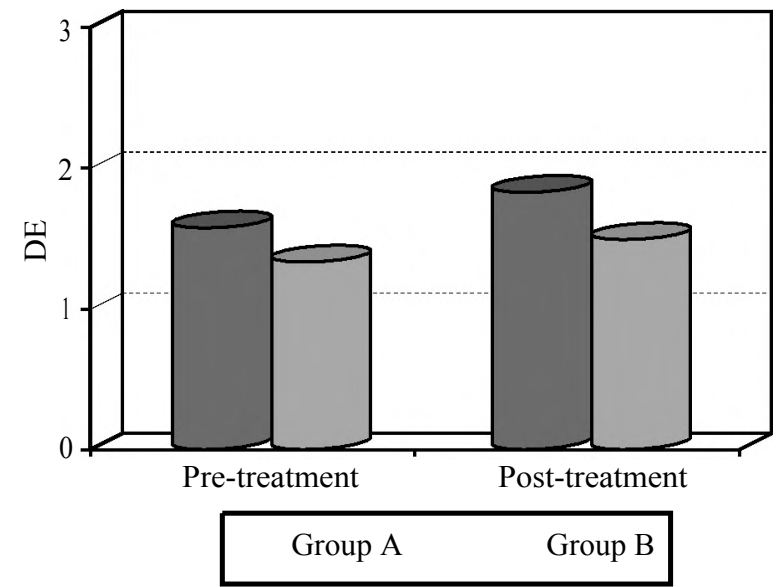

Fig. (2): Show mean values of DE for Group A and Group B.

Average of improvement percentage for Groups (A) and $(B)$ :

Table (3): Average of improvement percentage for Group A and $\mathrm{B}$.

\begin{tabular}{lcc}
\hline \multirow{2}{*}{ Items } & \multicolumn{2}{c}{ Percentage of improvement } \\
\cline { 2 - 3 } & $\begin{array}{c}\text { Pulmonary function } \\
\text { tests (Group A) }\end{array}$ & $\begin{array}{c}\text { Diaphragmatic } \\
\text { excursion (Group B) }\end{array}$ \\
\hline FVC & $11.06 \%$ & $5.33 \%$ \\
DE & $15.92 \%$ & $12.03 \%$ \\
Average & $13.49 \%$ & $8.68 \%$ \\
\hline
\end{tabular}

As observed in Table (3), the overall mean value of FVC, FEV 1, FEV 1/FVC, and DE was $13.49 \%$ for (Group A). Moreover, in (Group B) the overall mean value of $\mathrm{FVC}, \mathrm{FEV}_{1}, \mathrm{FEV}_{1} / \mathrm{FVC}$, and DE was $8.68 \%$. The (Group A) recorded the best group.

\section{Discussion}

This study was assigned to evaluate the efficacy of myofascial release for diaphragm and intercostal muscles on vital capacity and diaphragmatic excursion in patients with post-surgical pleural effusion. Forty patients with post-operative pleural effusion were included in this study. All patients assigned randomly into two equal groups of 20 patients in each group. (Study Group A): Consisted of 20 patients diagnosed as post-operative pleural effusion and were enrolled in the myofascial release protocol in addition to traditional physical therapy program for pleural effusion. (Study Group B): consisted of 20 patients diagnosed as post-operative pleural effusion and were enrolled only in traditional physical therapy program for pleural effusion. The myofascial release protocol in this study was performed 3 times a week for 8 weeks. Spirometery and ultrasonography and were used to measure the vital capacity and diaphragmatic excursion \& were done for all patients participated in this study pre- 
treatment and after 8 weeks of the treatment program.

The results of the present study represent average of improvement percentage for Group (A) and (B): Group (A) myofascial release group, showed a statistical significant improvement in vital capacity and diaphragmatic excursion, that was $13.49 \%$, more than the improvement in Group (B) traditional physical therapy group, that was $8.68 \%$. The Group A recorded the best group.

Claudia, [13] mentions that increasing the excursion of the chest by $1 \mathrm{~cm}$ will increase the volume of air exchanged by $200 \mathrm{cc}$ and improve lung function and capacity.

For this reason, this work try to find a appropriate technique to improve diaphragmatic excursion and vital capacity in patients with post-surgical pleural effusion.

The results of this study coincided with the results achieved by Rocha et al., [12] who concluded that the manual diaphragm release technique improves diaphragmatic mobility, exercise capacity and inspiratory capacity in people with chronic obstructive pulmonary disease.

The results of this study coincided with the results achieved by Abdelaal et al., [14] who concluded that diaphragmatic and costal manipulation counteract COPD changes and increase chest wall compliance as stretching of the respiratory muscles can improve chest wall mobility, improve vital capacity and reduce dyspnea.This manual techniques were introduced to improve pulmonary function, these components of pulmonary system.

The results of this study followed Vikram et al., [15] that showed significant improvement FEV 1 and FVC in healthly male subjects after intercostal stretch.

The results of this study coincided with the results achieved by Claudia, [13] who concluded that the intercostal rib technique offers an additional option in the treatment of both acute and chronic asthmatic patient. There is no interference with pharmacological or medical management. The work of breathing is decreased.

In agreement with the results of the current study, Hollis, [16] suggests that the periodic application of diaphragm stretching treatment in patients with respiratory disorders, improve the elastic capacity of the respiratory muscles and reduces the morbidity from theses conditions, in addition to medication.
The results of this study coincided with the results achieved by Charlotte et al., [17] who concluded that respiratory muscle strength was not impaired, either before or two months after cardiac surgery. The reason for post-operative lung function alteration is not yet known. Interventions aimed at restore an optimal postoperative lung function should focus on other interventions then respiratory muscle strength training.

\section{Conclusions:}

The myofascial release of the intercostal muscles and diaphragm is effective in improving vital capacity and increasing of the diaphragmatic excursion in patients with post-operative pleural effusion and hence decrease the risk of the plumonary complications and improve the quality of life.

\section{References}

1- KAMRAN BOKA, GUY W. SOO HOO, RUBIN JEFFREY, HAROLD L. MANNING and STEPHEN PETERS Pleural Effusion. Medscape. Retrieved Jul. 20, 2017. emedicine.medscape.com/article/299959-overview, 2017.

2- LEDUC D. DIMITRI and De TROYER ANDRÉ: Function of the canine inspiratory muscle pump in pleural effusion: Influence of body position. J. Appl. Physiol., 114: 941 7, 2013.

3- MORENO M.A., CATAI A.M., TEODORI R.M., BORGES B.L., CESAR MDE C. and Da SILVA E.: Effect of a muscle stretching program using the global postural reeducation method on respiratory muscle strength and thoraco-abdominal mobility of sedentary young males. J. Bras. Pneumol., 33 (6): 679-86, 2007.

4- KOPACZ and NATALIA: Educational course of deep tissue massage and myofascial release techniques for SAMK physiotherapy students. Samk, Satakunta University of Applied Sciences. Degree Programme in Physiotherapy December 2010 Number of pages: 39 Appendices: 10, 2010.

5- SALVI SHAH and AKTA BHALARA: Myofascial Release. International Journal of Health Sciences and Research (IJHSR) Vol. 2; Issue: 2, 2012.

6- GUNJAL S.B., SHINDE N.K. and KAZI A.H.: Effectiveness of deep breathing versus segmental breathing exercises on chest expansion in pleural effusion. Int. J. Health Sci. Res., 5 (7): 234-40, 2015.

7- NORMANDO V.M., BRITO M.V. and ALBUQUERQUE B.C.: Effects of pneumoperitoneum on the amplitude of diaphragmatic excursion in pigs, J. Bras. Pneumol., 32 (1): p. 16-22, 2006.

8- JUNG K.J., PARK J.Y., HWANG D.W., KIM, J.H. and KIM J.H.: Ultrasonographic diaphragmatic motion analysis and its correlation with pulmonary function in hemiplegic stroke patients. Ann. Rehabil. Med., 38: 29-37, 2014.

9- FAHY BONNIE, MARIANNA SOCKRIDER, SUZANNE LAREAU, MARIANNA SOCKRIDER and BRIAN GRAHAM: Pulmonary function tests. ATS Patient Education Series. Am. J. Respir. Crit. Care Med., Vol. 189, P17P18, 2014. 
10- MATAMIS D., SOILEMEZI E., TSAGOURIAS M., AKOUMIANAKI E., DIMASSI S., BOROLI F., RICHARD J.C. and BROCHARD L.: Sonographic evaluation of the diaphragm in critically ill patients. Technique and clinical applications," Intensive Care Medicine, Vol. 39, No. 5, pp. 801-10, 2013.

11- STANBOROUGH MICHAEL, ROBERT SCHLEIP and PETER O'REILLY: Direct Release Myofascial Technique: An Illustrated Guide for Practitioners.1 St Edition, 2004.

12- ROCHA T., SOUZA H., BRANDÃO D.C., RATTES C., RIBEIRO L., CAMPOS S.L., ALIVERTI A. and De ANDRADE A.D.: The manual diaphragm release technique improves diaphragmatic mobility, inspiratory capacity and exercise capacity in people with chronic obstructive pulmonary disease: A randomised trial. J. Physiother, 61 (4): 182-9, 2015.

13- CLAUDIA L. McCARTY: Intercostal rib release. The AAO Journal/29, 2016.
14-ABD EL-AAL ASHRAF, ALI MOHAMED and HEGAZY IBRAHIM: Effect of diaphragmatic and costal manipulation on pulmonary function and functional capacity in chronic obstructive pulmonary disease patient, 2015

15- VIKRAM MOHAN, KU BADLISYAH KU AZIZ, KAMARIA KAMARUDDIN, JOSEPH H. LEONARD and GOPAL JAGANNATHAN: Effect Of Intercostal Stretch On Pulmonary Function Parameters Among Healthy Males. Excli Journal, 11: 284-90, 2012.

16- HOLLIS HAND KING: The Somatic Connection. The Journal of the American Osteopathic Association July, Vol. 115, No. 7, 2015.

17- CHARLOTTE URELL, MARGARETA EMTNER, HANS HEDENSTROM and ELISABETH WESTERDAHL: Respiratory muscle strength is not decreased in patients undergoing cardiac surgery. Journal of Cardiothoracic Surgery, $11: 41,2016$.

\section{كفاءة تحريك الآنسجة الرخوة على السعة الحيوية

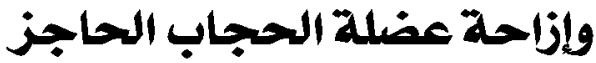 لدى مرضى الإرتشاح الرئوى بعد الجراحات الجزات}

\footnotetext{
كان الهدف من هذه الدراسة تقييم كفاعة تصريك الآنسجة الرخوة لعضلات ما بين الضلوع وعضلة الحجاب الحاجز على السعة الحيوية وعلى إزاحة عضلة الحجاب الحاجز لدى مرضى الإرتشاح الرئنى بعد الجراحات.

الآساليب: آجريت الدراسة على آربعين مريض تراوحت آعمارهم من • ع-7.7 سنة. تم تقسيم المرضى عشوائيا إلى مجموعتين متساوية

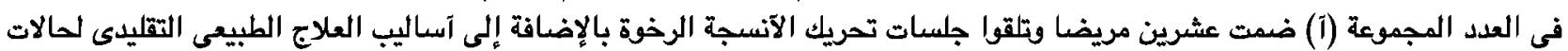

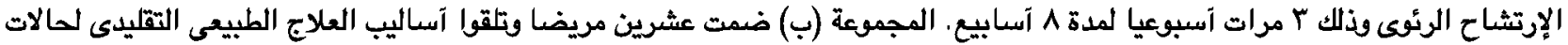
الإرتثاح الرئوى فقط. تم تقييم البيانات المتعلقة بقياس وظائف التفس وإئزاحة عضلة الحجاب الحاجز قبل وبعد الدراسة.

نتائج البحث: آظهرث النتائج وجود تصسنا ذات دلالة إحصائية في كلا من قياس السعة الصيوية وإزاحة عضلة الحجاب الحاجز فى نتائج المجموعة الآولى يفوق التحسن في نتائج المجموعة الثانية.

الإستتاج: تصريك الآنسجة الرخوة له تآثير إيجابى على السعة الصيوية وعلى إزاحة عضلة الحجاب الحاجز لدى مرضى الإرتشاح الرئوى 